\title{
Quality changes during ripening of Gouda cheese coated with loess
}

\author{
Ji-Hoon Na, Choul-Gyo Lee, Sang-Jun Park, Je-Hee Jeong, Cheol-Min Kim, \\ Hong-Bi Han, Bok-Seon Kim, Chang-Ki Huh* \\ Department of Food Science and Technology, Sunchon National University, Suncheon 57922, Korea
}

\section{황토 코팅 가우다 치즈의 숙성 중 품질특성 변화}

\author{
나지훈·이철교 · 박상준 · 정재희 · 김철민 · 한홍비·김복선 · 허창기* \\ 순천대학교 식품공학과
}

\begin{abstract}
The aim of this study was to develop a loess-coated ripening system for Gouda cheese. The quality characteristics of the coated Gouda cheese one and two months after the ripening were compared. The moisture content of loess was the lowest in white clay (WL). The antifungal effect of WL was slightly higher than that of the other samples. It was confirmed that the heavy metal content in the loess was within the soil pollution concern standard and countermeasure standard. The content of $\mathrm{NH}_{3}-\mathrm{N}$ was the lowest at $143.51 \mathrm{mg} \%$ in $\mathrm{WL}$ followed by $204.88 \mathrm{mg} \%$ in red loess (RL). Gouda cheese is a hard cheese. In the present study, the moisture content after 60 days of ripening was within the range for WG (WL-coated Gouda cheese after ripening) only. During ripening, the pH and titratable acidity of the cheese increased in all samples. The mineral contents of the cheese increased in the order of $\mathrm{Na}$, $\mathrm{Ca}$, $\mathrm{Mg}$, and $\mathrm{K}$. The $\mathrm{NH}_{3}-\mathrm{N}$ content of the $\mathbf{~} \mathrm{G}$ (laterite-coated Gouda cheese after ripening) was lowest after 60 days of ripening. The WG showed the greatest reduction in $\mathrm{NH}_{3}-\mathrm{N}$ content from 30 to 60 days of ripening. The heavy metal content in the Gouda cheeses coated with loess and ripening was within the food standard range.
\end{abstract}

Key words : loess, Gouda cheese, ripening, coating system, quality

\section{서 론}

치즈는 우유, 크림 등에 유산균, 린넷, 산 등을 첨가하여 유제품 속의 카제인을 응고시켜 유청을 제거 및 압축, 성형 하여 만들어진 응고물 또는 발효 숙성 유제품을 말한다(1). 치즈 품질은 제조할 때 사용하는 원유(raw milk), 미생물, 효소 및 공정, 제조지역 등에 따라 맛, 향, 형태 등이 차이가 있으며, 대략 1,000 종 이상이 생산되고 있다고 보고되어 있다(2-5).

가우다 치즈는 네덜란드 Rotterdam Gouda 지방에서 만들

*Corresponding author. E-mail : hck1008@sunchon.ac.kr Phone : 82-61-750-3251, Fax : 82-61-750-3208

Received 07 May 2019; Revised 10 June 2019; Accepted 01 July 2019.

Copyright (c) The Korean Society of Food Preservation. All rights reserved.
어지는 전통적 자연치즈 중의 하나로써 네덜란드의 예담 치즈와 함께 유명한 주요 수출 농산품 중의 하나이다 $(6,7)$. 국내에서는 2015년 국내 소비자들이 구입한 치즈 종류의 순위를 보면 체다 치즈, 모차렐라 치즈, 크림 치즈, 카망베르 치즈, 가우다 치즈 순이었으나 가공치즈 제조에 활용되는 체다 치즈, 신선치즈인 모차렐라 치즈와 크림 치즈, 곰팡이 배양치즈인 카망베르 치즈를 제외하고는 숙성 치즈로는 가우다 치즈가 우리 국내 소비자들에게 가장 인기가 있는 치즈로서 한국인의 입맛에 잘 맞는 치즈 이다(8).

가우다 치즈는 최소 2-6개월 이상 숙성시키는 전통적 숙성 치즈로서 신맛을 가지며, 겉 표면은 약간 딱딱한 원형 또는 원반형의 모양을 띄며, 일반적으로 담황색의 파라핀 이나 왁스 등으로 코팅하여 숙성시킨다(9). 숙성을 시킬 시 곰팡이는 일부 치즈를 제조할 때 첨가되어 특이적 외형 과 풍미 등을 제공하나, 대부분의 치즈에서는 부패 또는 변패의 원인이 된다. 곰팡이 오염은 직접적 치즈 오염 또는 
우유의 간접적 오염을 통해 Aspergillus, Fusarium, Penicillium 속과 같은 원치 않는 곰팡이를 생산하고 이를 통해 오크라톡신 $\mathrm{A}$ 와 아플라톡신 $\mathrm{M} 1$ 과 같은 위험한 독소 를 생산할 수 있다(10). 또 숙성 진행시 Grappin 등(11)과 Yamauchi 등(12)에 따르면 단백질 분해효소 시스템에 의해 서 수용성 질소, 비단백태 질소, 아미노태 질소의 함량이 증가한다고 보고하였다. 가우다 치즈는 선반 위에서 습도 $85 \%$ 온도 $13-15^{\circ} \mathrm{C}$ 를 유지하면서 지속적으로 뒤집어 주며 숙성을 진행하고, 이러한 숙성과정에서 수용성 질소화합물 과 유리지방산 등을 만들어 특유의 풍미를 생성한다. 또 숙성 진행시 잡균 오염 및 수분이 증발 하는 것을 억제하기 위해 왁스 코팅을 이용하게 되며(13), 이러한 숙성 방법은 지속적으로 뒤집어 주어야 하는 번거로움 및 국내 소비자들 에게 낮선 특유 향을 생성하게 되는데, 이를 억제하여 소비 자들의 기호성을 높이며, 동시에 숙성과정의 번거로움을 해소 할 수 있는 숙성 방법의 개발이 필요할 것으로 생각되 어 진다.

황토는 두 가지 의미로 사용되고 있으며, 일반적 의미로 는 “빛깔이 누르고 거무스름한 흙"을 의미한다. 즉, 황색 또는 황갈색의 흙을 의미하며, 학술적으로는 "바람에 의해 운반되어 퇴적된 담황색 또는 황회색을 띠는 실트질 퇴적물 (Loess)"을 말하며(14), 풍화산물로 주로 $\mathrm{Mg}, \mathrm{Si}, \mathrm{Al}, \mathrm{Fe}$, $\mathrm{Na}, \mathrm{K}, \mathrm{Ca}, \mathrm{Mn}$ 의 산화물성분이 대부분을 차지하며, 그 외 소량의 미량성분들을 포함한다. 이는 암석의 종류 및 풍화 에 따라 차이가 나타날 수 있으며, 색과 성분 그리고 물리화 학적 성질 등 또한 다양하게 나타날 수 있다 $(15,16)$.

황토는 건조, 반건조 지역에 널리 분포하는 광물로서 지 구 표면의 $10 \%$ 정도를 차지하고 있다. 다공성 구조를 가져 탈취, 흡착, 항균, 완충작용, 원적외선 방사, 이온교환 등의 기능을 보유하고 있어 건축소재, 화장품 첨가제, 건강증진 을 목적으로 하는 제품들에 많이 사용되고 있다 $(17,18)$. 하 지만 황토를 활용하여 자연 치즈를 숙성시키는 등의 치즈에 접목한 연구는 현재 미흡하며, 추가적인 연구가 이루어 져 야하는 실정이다.
따라서 본 연구에서는 황토를 이용하여 자연 치즈의 숙 성 과정 중 발생 할 수 있는 곰팡이균의 생성을 억제 또는 제거할 수 있는 방법을 모색함과 동시에 숙성 과정에서 발생하는 NH3-N의 함량을 감소시키는 방법을 구상하며, 이를 통하여 국내의 자연치즈 생산 기술을 확보하고, 추가 적으로 다양한 종류의 자연치즈 숙성 방법에 응용함으로써 원유의 활용성 증대에 기여하고자 이 연구를 수행하였다.

\section{재료 및 방법}

\section{실험 재료}

본 실험에 사용한 황토는 (주고창황토(Gochang, Korea)에 서 325 mesh 홍토(LL, Laterite), 적황토(RL, Red loess), 호황 토(YL, Yellow ocher), 백토(WL, White clay), 흑토(BL, Black soil)를 각각 구매하여, 총 5가지 황토(오색토)를 구매 하여 실온보관하면서 사용하였다. 시약과 배지는 Sulfuric acid, nitric acid, sodium nitroferricyanide dihydrate, phenol, sodium hypochlorite, sodium hydroxide, ethyl ether는 Deajung사(Siheung, Korea)의 것을 구입하여 사용하였으며, disodium hydrogenphosphate 12-water은 Junsei Chemical Co., Ltd.사(Tokyo, Japan)의 것을 사용하였다. Potato Dextrose Broth(PDB)는 Difco사(Detroit, MI, USA)의 것을 구입하여 사용하였다.

\section{가우다 치즈의 황토 코팅과 숙성 방법}

가우다 치즈는 (재)임실치즈\&식품연구소에서 $300 \mathrm{~g}$ 단 위로 당일 제조된 치즈를 구입하여 $4^{\circ} \mathrm{C}$ 냉장고에서 1 일간 예비 건조를 시킨 후 2 일째에 사용하였으며, 황토 코팅은 Fig. 1과 같이 실시하였다. 먼저 각각의 종류별 황토(오색 토)에 0.5 $1.0 \mathrm{~cm}$ 단위로 자른 볏짚(Suncheon, Korea)과 증 류수를 혼합하여 멸균시켰으며, 가우다 치즈를 한지로 감 싸고 멸균시킨 황토 볏짚 혼합액을 한지에 감싸인 가우다 치즈에 고르게 도포한 뒤, $1-2$ 일간 물기가 충분히 마르도록

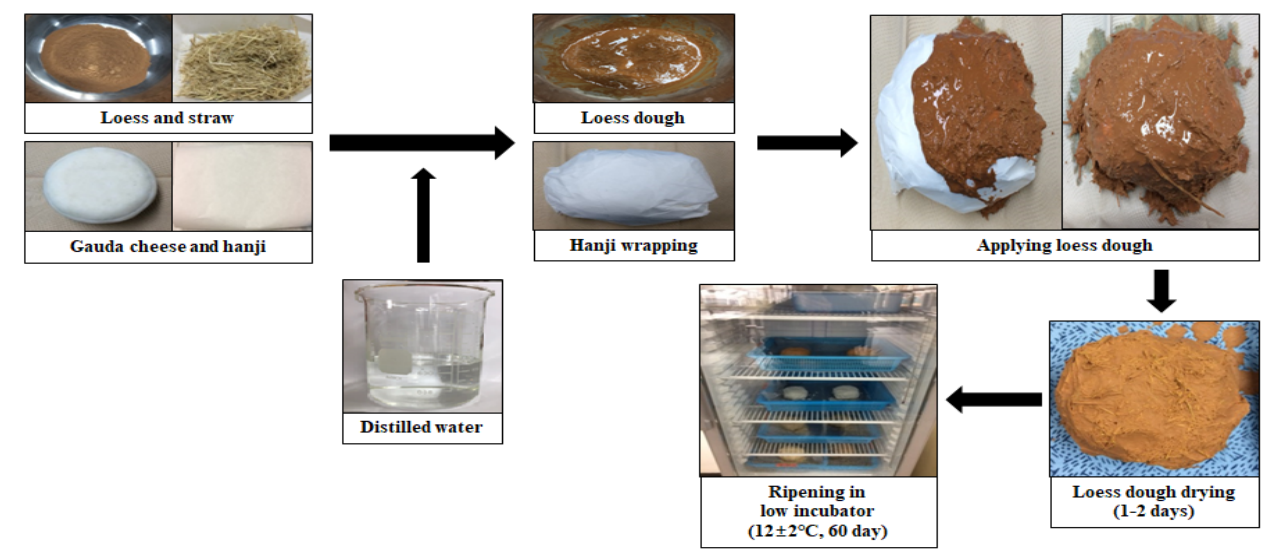

Fig. 1. Manufacture method of Gouda cheese coated with loess. 
건조하였다. 건조가 끝난 치즈는 저온 숙성고(CSR470RD1W, Carrier, Gurisi, Korea)에서 $12^{\circ} \mathrm{C}$ 를 유지하면서 제조 직후, 30 일 및 60 일 숙성한 치즈의 품질을 평가하였다. 60 일 숙성된 각 치즈의 외관 모습은 Fig. 2 와 같다. 시료구 구성은 코팅 하지 않고 숙성한 가우다 치즈(CG), 진공 포장 해 숙성한 가우다 치즈(VG), 홍토로 코팅해 숙성한 가우다 치즈(LG), 적황토로 코팅해 숙성한 가우다 치즈(RG), 황토 로 코팅해 숙성한 가우다 치즈(YG), 백토로 코팅해 숙성한 가우다 치즈(WG), 흑토로 코팅해 숙성한 가우다 치즈(BG) 로 구성되었으며, 숙성 60 일째 시료구별 외관을 관찰한 결 과 코팅 하지 않고 숙성한 치즈는 치즈 전면에 곰팡이가 발생하였고, 그 외 시료구는 곰팡이가 확인 되지 않았다. 시료구별 품질 분석에는 치즈 외피에서 안쪽 부분으로 2-3 $\mathrm{mm}$ 제거한 후 사용하였다.

\section{일반성분 측정}

일반성분은 $\mathrm{AOAC}$ 법(19)에 의하여 분석하였다. 즉, 수분 함량은 $105^{\circ} \mathrm{C}$ 에서 상압건조법, 회분 함량은 $550^{\circ} \mathrm{C}$ 에서 직 접회화법을 이용하여 분석하였다. 조단백질 함량은 micro-Kjeldahl법을 이용한 단백질 자동분석기로 분석하였 으며, 질소계수 6.38 을 곱하여 계산하였다. 조지방 함량은 Soxhlet법을 이용하여 분석하였다.

\section{황토의 항곰팡이 활성 측정}

황토의 항곰팡이 효과를 측정하기 위하여 실험 균주는 순천대학교 식품미생물실험실에서 보관 중인 Penicillium candidum(SWUNG FD PCA-3(10U), Chr. Hansen SA, France)을 PDB(PDB; Difco)배지를 이용하여 $100 \mathrm{~mL}$ 기준 으로 제조하여 $25^{\circ} \mathrm{C}$ 에서 48 시간 액체 배양하여 사용하였 다. 항곰팡이 효과 실험은 Kang 등(20)의 방법을 참고하여 측정하였다. Potato Dextrose Broth(PDB; Difco) 배지를 30 $\mathrm{mL}$ 기준에 수분을 건조시킨 황토 $1 \mathrm{~g}$ 을 첨가하여 배지에 혼합한 후 멸균하고, 멸균한 배지에 P. candidum 배양액을
$10^{5} \mathrm{cfu} / \mathrm{mL}$ 로 희석한 여액 $1 \mathrm{~mL}$ 을 첨가하여 $25^{\circ} \mathrm{C}$ 에서 48 시 간 배양하였다. 이 배양액을 건조한 후 칭량하고, 이 값에서 배지에 첨가한 무수 황토 무게를 뺀 값을 균체량으로 결정 하였다.

\section{중금속 함량 측정}

황토와 가우다 치즈의 중금속 함량 측정은 건식분해법 (21)으로 전처리하여 분석 하였다. 즉, 시료 $1 \mathrm{~g}$ 을 칭량하여 $550-600^{\circ} \mathrm{C}$ 로 회화 시킨 후 황토의 경우 증류수 $1 \mathrm{~mL}$ 와 $\mathrm{HCl}$ $10 \mathrm{~mL}$ 을 가하였고, 치즈의 경우 증류수 $1 \mathrm{~mL}$ 와 질산 0.5 $\mathrm{mL}$ 를 가하여 백연현상이 일어날 때 까지 가열 시킨 다음 질산 $0.5 \mathrm{~mL}$ 를 가한 후 증류수로 $100 \mathrm{~mL}$ 로 정용하여 검액 으로 하였다. 각 중금속 측정은 ICP-OES(iCAP 7400 DUO, Thermo Fisher Scientific, Cambridge, UK)로 각 원소의 표준 용액 농도를 1,3 및 $5 \mathrm{ppm}$ 으로 조제하여 표준검량 곡선을 작성하여 분석하였다.

\section{$\mathrm{NH}_{3}-\mathrm{N}$ 함량 측정}

$\mathrm{NH}_{3}-\mathrm{N}$ 함량은 $\mathrm{Hwang}(22)$ 의 실험에서와 같이 시료 $3 \mathrm{~g}$ 에 증류수 $30 \mathrm{~mL}$ 을 가하여 균질화 한 뒤 감압 여과하고, 그 여액을 $1 \mathrm{~mL}$ 취하여 phenol-hypochloride 반응에 의하여 $\mathrm{A}$ 용액 $\left(\mathrm{C}_{6} \mathrm{H}_{6} \mathrm{O} 10 \mathrm{~g}\right.$ 과 $\mathrm{C}_{5} \mathrm{H}_{4} \mathrm{FeN}_{6} \mathrm{Na}_{2} \mathrm{O}_{3} 0.05 \mathrm{~g} /$ distilled water $1 \mathrm{~L})$ 과 $\mathrm{B}$ 용액 $\left(\mathrm{Na}_{2} \mathrm{HPO}_{4} \cdot 12 \mathrm{H}_{2} \mathrm{O} 9 \mathrm{~g}, \mathrm{NaOH} 6 \mathrm{~g}\right.$ 과 $\mathrm{NaOCl}$ $10 \mathrm{~mL} /$ distilled water $1 \mathrm{~L}$ )을 각각 $2 \mathrm{~mL}$ 씩 넣고 $37^{\circ} \mathrm{C}$ 에서 20분간 반응시켜 흡수 분광 광도계((Hewlett Packard 8453, Waldbronn, Germany)를 이용하여 $630 \mathrm{~nm}$ 에서 흡광도를 측정하였으며, ammonium sulfate를 이용하여 표준곡선을 토대로 $\mathrm{NH}_{3}-\mathrm{N}$ 함량을 계산하였다.

\section{$\mathrm{pH}$ 및 적정 산도 측정}

가우다 치즈의 $\mathrm{pH}$ 측정은 $\mathrm{pH}$ meter(ATI ORION 940, Boston, MA, USA)를 사용하였다. 즉 시료 $5 \mathrm{~g}$ 을 취하고 증류수 $10 \mathrm{~mL}$ 를 가하여 분쇄기를 통하여 분쇄 후 $\mathrm{pH}$ meter

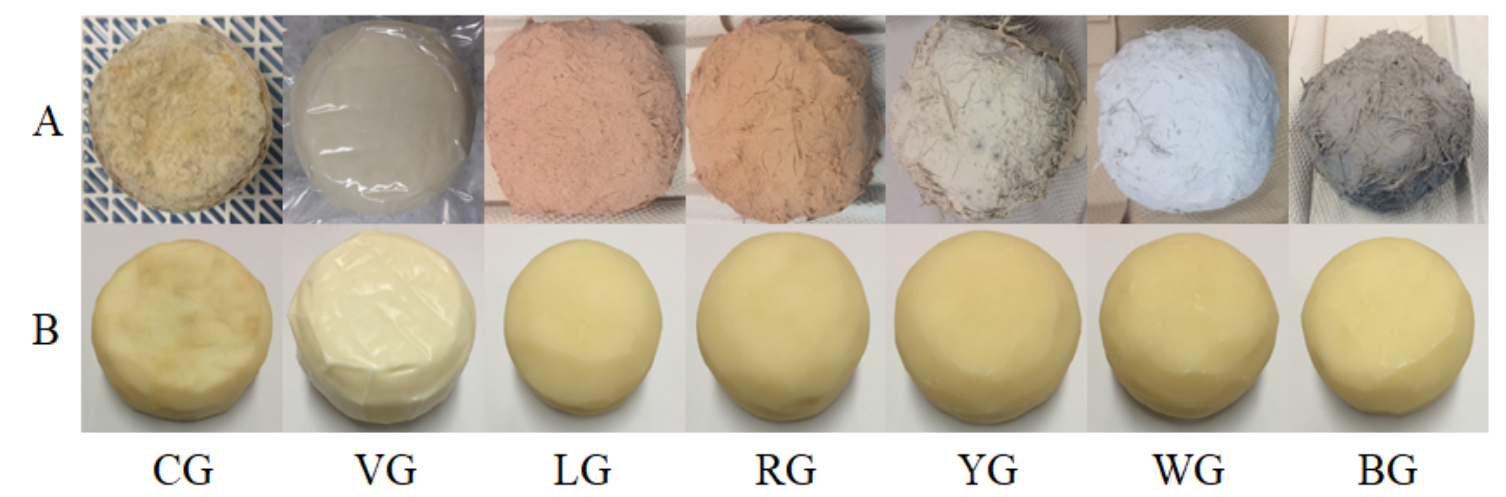

Fig. 2. The appearance of Gouda cheese after ripening 60 days.

A, Before surface removal; B, After surface removal. CG, Gouda cheese of ripening without coating, VG, Gouda cheese of ripening after vacuum packaged; LG, Gouda cheese of laterite coating ripening ; RG, Gouda cheese of red loess coating ripening; YG, Gouda cheese of yellow ocher coating ripening; WG, Gouda cheese of white clay coating ripening; BG, Gouda cheese of black soil coating ripening. 
를 사용하여 측정하였다. 적정 산도 측정은 시료 $5 \mathrm{~g}$ 을 취하 고 증류수 $10 \mathrm{~mL}$ 을 가하여 감압 여과한 후 $1 \mathrm{~mL}$ 를 취해 $0.1 \%$ phenolphthalein을 지시약으로 하여 $0.1 \mathrm{~N} \mathrm{NaOH}$ 용액 으로 중화 적정하고 organic acid로 환산하여 산도(\%)를 나 타내었으며, 이 때 젖산의 농도는 $0.1 \mathrm{~N} \mathrm{NaOH} 1 \mathrm{~mL}$ 를 $0.009 \mathrm{~g}$ 으로 계산하여 백분율(\%)로 환산하여 나타내었다.

\section{무기성분 측정}

가우다 치즈의 무기성분은 건식분해법(21)으로 전처리 하여 분석 하였다. 즉, 시료 $0.5 \mathrm{~mL}$ 를 칭량하여 $550-600^{\circ} \mathrm{C}$ 로 회화 시킨 후 증류수 $1 \mathrm{~mL}$ 와 질산 $0.5 \mathrm{~mL}$ 를 가하여 heating plate에서 백연현상이 일어날 때 까지 가열 시킨 다음 질산 $0.5 \mathrm{~mL}$ 를 가한 후 증류수로 $100 \mathrm{~mL}$ 로 정용하여 검액으로 하였다. 각 무기성분의 정량은 원자흡광비색계(Perkin Elmer Analyst 300, Perin Elmer Co., Norwalk, CT, USA)로 각 원소의 표준용액 농도를 1,3 및 $5 \mathrm{ppm}$ 으로 조제하여 표준검량 곡선을 작성하여 분석하였다.

\section{통계분석}

실험결과는 3회 반복 측정하여 $\operatorname{SPSS} \operatorname{program}(25, \mathrm{IBM}$ Corp Armonk, NY, USA)을 사용하였고, mean $\pm \mathrm{SD}$ 를 구하 였으며, Duncan's multiple range test로 시료간의 유의차를 분석하였다.

\section{결과 및 고찰}

\section{황토의 품질 특성}

황토의 품질특성 측정 결과는 Table 1 및 Fig 3 과 같다. 먼저 황토 종류에 따른 수분함량 측정 결과는 Table 1 과 같다. 황토의 수분함량은 홍토 $3.48 \%$, 흑토 $3.31 \%$, 적황토 $1.56 \%$, 호황토 $0.95 \%$, 백토 $0.22 \%$ 로 홍토의 수분 함량이 가장 높게 나타났으며 백토가 가장 낮은 수분함량으로 나타 났다. Park(23)에 따르면 우리나라의 비습도와 상대습도는
계절별 지역별 차이가 있다고 보고되어 지며, 이러한 비습 도와 상대습도의 차이는 황토의 종류, 채취 지역, 시기 등에 따라 황토의 수분함량에 영향을 준 것으로 생각되어 진다. P. candidum을 배양한 배양액을 건조한 후 칭량한 황토 종류에 따른 항곰팡이 효과에서 공시험의 경우 $0.61 \mathrm{~g} / 30$ $\mathrm{mL}$ 로 나타났으며, 백토가 $0.56 \mathrm{~g} / 30 \mathrm{~mL}$, 적황토가 $0.57 \mathrm{~g} / 30$ $\mathrm{mL}$, 적황토와 흑토가 $0.59 \mathrm{~g} / 30 \mathrm{~mL}$, 호황토가 $0.60 \mathrm{~g} / 30$ $\mathrm{mL}$ 로 나타나 전체적으로 배양액에 황토를 첨가하였을 때 항곰팡이 효과가 있는 것을 확인 할 수 있었다. Byrne와 $\mathrm{Ward}(24)$ 이 보고한 바와 같이 황토를 첨가함으로써 작은 pellet 크기가 형성되어, 균체의 성장에는 유리하지만, 배양 액의 점성이 증가하여 산소와 영양분 공급이 방해되어 공시 험 보다 더 좋은 항곰팡이 효과를 보인 것으로 생각되어 진다. 또한 황토 시료구 중 백토의 항곰팡이 효과가 0.56 $\mathrm{g}$ 으로 가장 높은 항곰팡이 효과가 나타났으며, Lee(25)의 보고에 의하면 백토 첨가 샘플에서는 $S$. aureus, $P$. aeruginosa, E coil, C. albicans균의 생성 저해 효과를 나타 냈고, 방부력 실험에서도 백토 함유 샘플이 일반 샘플(백토 를 함유하지 않은 샘플)보다 더 좋은 효과가 나타난다고 하여 이와 유사한 결과로 생각된다. 이를 통해서 가우다 치즈를 왁스 코팅하여 숙성 할 때 곰팡이 균의 생성을 억제 함으로써 자주 뒤집어 주어야 하는 번거로움을 황토로 코팅 하면서 어느 정도 해소 할 수 있을 것으로 생각되며, 이러한 곰팡이 균 억제 효과는 다른 숙성 치즈의 제조 방법에도 응용하여 사용함으로써 국내 숙성 치즈 제조 기술 발전에 기여할 수 있을 것으로 생각되어진다. 황토의 중금속 측정 결과 $\mathrm{Pb}, \mathrm{Sn}, \mathrm{Cr}, \mathrm{Cu}$ 네 가지 중금속 성분이 검출 되었으나, 토양 오염 우려기준 및 대책 기준(26)을 확인 하였을 때 5 가지 황토 시료구 모두 $\mathrm{Pb}, \mathrm{Cd}, \mathrm{As}, \mathrm{Hg}, \mathrm{Sn}, \mathrm{Cr}, \mathrm{Cu}$ 7가지 중금속 성분에 대해 적합한 것을 확인 할 수 있었다. 황토의 $\mathrm{NH} 3-\mathrm{N}$ 함량 측정 결과는 Fig 2와 같다. 백토의 $\mathrm{NH}_{3}-\mathrm{N}$ 함량 이 $143.51 \mathrm{mg} \%$ 로 가장 낮은 함량을 보였으며, 그 다음으로 적황토가 $204.88 \mathrm{mg} \%$ 로 낮은 함량을 보였다. 또 홍토와 흑토가 각각 $286.50 \mathrm{mg} \%, 287.88 \mathrm{mg} \%$ 로 가장 높은 $\mathrm{NH}_{3}-\mathrm{N}$ 함량을 보였다.

Table 1. Quality characteristics of loess

\begin{tabular}{|c|c|c|c|c|c|c|c|c|c|}
\hline \multirow{2}{*}{ Samples } & \multirow{2}{*}{$\begin{array}{l}\text { Moisture } \\
(\%)\end{array}$} & \multirow{2}{*}{$\begin{array}{l}\text { Mold inhibit effect } \\
\qquad(\mathrm{g} / 30 \mathrm{~mL})\end{array}$} & \multicolumn{7}{|c|}{ Heavy metal $(\mathrm{mg} / \mathrm{L})$} \\
\hline & & & $\mathrm{Pb}$ & $\mathrm{Cd}$ & As & $\mathrm{Hg}$ & $\mathrm{Sn}$ & $\mathrm{Cr}$ & $\mathrm{Cu}$ \\
\hline $\mathrm{LL}^{1)}$ & $3.48 \pm 0.28^{\mathrm{a} 2 / 3)}$ & $0.59 \pm 0.00^{c}$ & $0.024 \pm 0.009^{d}$ & - & - & - & $0.027 \pm 0.007^{\mathrm{a}}$ & $0.184 \pm 0.001^{b}$ & $0.198 \pm 0.001^{\mathrm{a}}$ \\
\hline RL & $1.56 \pm 0.06^{\mathrm{b}}$ & $0.57 \pm 0.00^{\mathrm{d}}$ & $0.071 \pm 0.010^{b}$ & - & - & - & $0.027 \pm 0.004^{\mathrm{a}}$ & $0.202 \pm 0.001^{\mathrm{a}}$ & $0.154 \pm 0.002^{c}$ \\
\hline YL & $0.95 \pm 0.04^{c}$ & $0.60 \pm 0.01^{b}$ & $0.161 \pm 0.005^{\mathrm{a}}$ & - & - & - & $0.001 \pm 0.001^{b}$ & $0.072 \pm 0.001^{\mathrm{e}}$ & $0.147 \pm 0.000^{d}$ \\
\hline WL & $0.22 \pm 0.02^{\mathrm{d}}$ & $0.56 \pm 0.01^{\mathrm{d}}$ & $0.044 \pm 0.010^{c}$ & - & - & - & $0.012 \pm 0.010^{b}$ & $0.096 \pm 0.001^{\mathrm{c}}$ & $0.125 \pm 0.001^{\mathrm{e}}$ \\
\hline $\mathrm{BL}$ & $3.31 \pm 0.10^{\mathrm{a}}$ & $0.59 \pm 0.00^{c}$ & $0.050 \pm 0.009^{\mathrm{c}}$ & - & - & - & - & $0.091 \pm 0.001^{\mathrm{d}}$ & $0.162 \pm 0.001^{b}$ \\
\hline BT & 4) & $0.61 \pm 0.00^{\mathrm{a}}$ & - & - & - & - & - & - & - \\
\hline
\end{tabular}

${ }^{1} \mathrm{LL}$, Laterite; RL, Red loess; YL, Yellow ocher; WL, White clay; BL, Black soil; BT, Blank test.

${ }^{2)}$ All values are mean $\pm \mathrm{SD}$.

${ }^{3}$ Means in the same column followed by different uppercase letters are significantly different $(p<0.05, a>b>c>d>e)$.

${ }^{4}$ Not tested or not detected. 


\section{일반성분}

가우다 치즈의 일반성분 측정 결과는 Table 2 와 같다. 가우다 치즈의 일반성분은 농촌진흥청 국립농업과학원 (27)에서 고시한 바와 같이 수분, 조지방, 조단백, 조회분 순으로 나타났으며, 조단백 및 조지방의 경우 고시된 함량 에 비해 다소 낮은 값을 보였다. Lee와 Nam(1)에 따르면 가우다 치즈를 plastic coating 처리하여 숙성 시 기간이 증가 할수록 단백질, 지방, 회분의 함량은 증가하고 수분은 감소 한다고 하였으며, 이는 수분함량의 감소에 따라 타 고형분 들의 함량이 상대적으로 증가하기 때문이라고 보고하였다. 하지만 황토 코팅 시 조단백의 경우 숙성 전에 비하여 숙성 후가 전체적으로 더 높은 함량을 보여 Lee와 Nam(1)이 보고 한 바와 같이 비슷하게 나타났으나, 수분의 함량은 코팅 없이 숙성시킨 가우다 치즈와 진공 포장 숙성 가우다 치즈 의 경우 큰 변화를 보이지 않았고, 황토 코팅 시료구 들에서 만 30 일 숙성 시 감소하였다가 이후 60 일 숙성한 가우다 치즈에서는 증가하는 경향을 보였다. 조지방 함량의 경우 30 일 숙성 시에는 초기 조지방 함량과 비교하였을 때 큰 차이를 보이지 않았으나, 이후 60 일 숙성 가우다 치즈에서 는 대부분의 황토 코팅 숙성 가우다 치즈들의 조지방 함량 이 감소하였다. 이를 통해 황토 코팅 숙성 가우다 치즈의 경우 수분과 지방이 코팅에 사용된 황토와 한지에 흡수 되면서 감소하지만, 초기에는 수분이 먼저 감소하면서 상 대적으로 수분 감소 비율이 크게 나타난 것으로 생각되며,
수분이 일정량 감소한 이후에는 가우다 치즈의 지방성분들 이 코팅 재료들에 흡수 되어 최종적으로 조지방 함량이 감소한 것으로 생각되어 진다. 가우다 치즈의 경우 치즈의 수분 함량에 따른 분류상 경질치즈에 포함되며 수분 함량이 25-36\% 내외로 고시되어 있다(28). 본 연구에서의 60 일 숙 성 후 수분 함량 측정 결과 백토로 코팅해 숙성한 가우다 치즈만 범위 내에 있었다.

\section{$\mathrm{pH}$ 및 산도}

가우다 치즈의 $\mathrm{pH}$ 및 적정 산도 측정 결과는 Table 3 과 같다. 숙성 전 가우다 치즈는 5.49 로 나타났으며, 숙성 가우 다 치즈의 $\mathrm{pH}$ 는 전체적으로 모든 시료구에서 증가하는 경 향을 보였다. Choi 등(29)이 보고한 바와 같이 숙성 기간이 경과함에 따라 치즈의 $\mathrm{pH}$ 가 증가하는 것을 확인할 수 있었 으며, 이 중에서 코팅 하지 않고 숙성한 가우다 치즈는 숙성 30 일 차에 $6.47,60$ 일 차에 7.01 로 숙성 전 가우다 치즈보다 다소 높은 $\mathrm{pH}$ 를 보였다. 이는 곰팡이가 번식함에 따라 치즈 의 부패가 진행되어 생긴 변화로 생각되어 진다.

가우다 치즈의 적정 산도 측정 결과 숙성 전 가우다 치즈 에서는 $0.115 \%$ 의 산도를 보였으며, 이후 숙성 30 일 차까지 는 큰 차이를 보이지 않았으나, 숙성 60 일 차에서는 적황토 코팅 숙성 가우다 치즈를 제외한 나머지 시료구에서 적정 산도가 증가한 것을 확인 할 수 있었다.

Table 2. Proximate composition of Gouda cheese coated with loess during ripening period

\begin{tabular}{|c|c|c|c|c|c|}
\hline \multicolumn{2}{|c|}{ Samples } & \multirow{2}{*}{$\begin{array}{c}\text { Moisture } \\
43.56 \pm 0.12^{223) 3}\end{array}$} & \multirow{2}{*}{$\begin{array}{c}\text { Crude protein } \\
10.35 \pm 0.95^{\mathrm{d}}\end{array}$} & \multirow{2}{*}{$\begin{array}{c}\text { Crude fat } \\
21.42 \pm 5.13\end{array}$} & \multirow{2}{*}{$\begin{array}{l}\text { Crude ash } \\
3.18 \pm 0.14^{\mathrm{a}}\end{array}$} \\
\hline Before ripening & 0 day & & & & \\
\hline \multirow{2}{*}{$\mathrm{CG}^{1)}$} & 30 day & $40.10 \pm 0.69^{\mathrm{ab}}$ & $11.68 \pm 0.36^{\mathrm{cd}}$ & $27.39 \pm 2.14^{b}$ & $1.75 \pm 0.05^{\mathrm{d}}$ \\
\hline & 60 day & $41.84 \pm 2.25^{\mathrm{ab}}$ & $11.55 \pm 0.28^{\text {cd }}$ & $15.56 \pm 2.63^{\mathrm{ab}}$ & $2.71 \pm 0.16^{b}$ \\
\hline \multirow{2}{*}{ VG } & 30 day & $43.73 \pm 0.64^{\mathrm{a}}$ & $11.59 \pm 1.15^{\mathrm{cd}}$ & $20.18 \pm 5.20^{\mathrm{ab}}$ & $2.32 \pm 0.42^{\mathrm{bc}}$ \\
\hline & 60 day & $42.95 \pm 1.19^{\mathrm{a}}$ & $10.60 \pm 0.88^{d}$ & $20.01 \pm 4.39^{\mathrm{ab}}$ & $2.72 \pm 0.28^{b}$ \\
\hline \multirow{2}{*}{ LG } & 30 day & $34.98 \pm 1.06^{\mathrm{d}}$ & $13.84 \pm 0.71^{\mathrm{a}}$ & $19.67 \pm 0.35^{\mathrm{ab}}$ & $2.49 \pm 0.15^{\mathrm{bc}}$ \\
\hline & 60 day & $41.20 \pm 0.22^{\mathrm{ab}}$ & $11.85 \pm 0.27^{\mathrm{bcd}}$ & $12.23 \pm 4.73^{b}$ & $3.28 \pm 0.17^{\mathrm{a}}$ \\
\hline \multirow{2}{*}{ RG } & 30 day & $34.46 \pm 1.20^{\mathrm{d}}$ & $10.90 \pm 0.39^{\mathrm{bcd}}$ & $18.82 \pm 1.24^{\mathrm{ab}}$ & $2.24 \pm 0.06^{\mathrm{c}}$ \\
\hline & 60 day & $38.89 \pm 2.43^{\mathrm{bc}}$ & $11.90 \pm 0.38^{\mathrm{bcd}}$ & $15.25 \pm 6.37^{\mathrm{ab}}$ & $3.44 \pm 0.26^{\mathrm{a}}$ \\
\hline \multirow{2}{*}{ YG } & 30 day & $35.15 \pm 2.85^{\mathrm{cd}}$ & $12.77 \pm 0.78^{\mathrm{d}}$ & $23.15 \pm 4.20^{a}$ & $2.56 \pm 0.15^{\mathrm{bc}}$ \\
\hline & 60 day & $40.18 \pm 0.38^{\mathrm{ab}}$ & $13.29 \pm 1.07^{\mathrm{ab}}$ & $20.27 \pm 1.33^{\mathrm{ab}}$ & $3.56 \pm 0.32^{\mathrm{a}}$ \\
\hline \multirow{2}{*}{ WG } & 30 day & $34.91 \pm 1.47^{\mathrm{d}}$ & $11.89 \pm 0.68^{\mathrm{bcd}}$ & $17.09 \pm 6.70^{\mathrm{ab}}$ & $2.22 \pm 0.24^{c}$ \\
\hline & 60 day & $35.77 \pm 5.24^{\mathrm{cd}}$ & $10.90 \pm 0.40^{\mathrm{d}}$ & $18.63 \pm 4.42^{\mathrm{ab}}$ & $3.52 \pm 0.12^{\mathrm{a}}$ \\
\hline \multirow{2}{*}{ BG } & 30 day & $35.21 \pm 2.78^{\mathrm{cd}}$ & $11.82 \pm 0.45^{\mathrm{abc}}$ & $20.07 \pm 0.33^{\mathrm{ab}}$ & $2.52 \pm 0.14^{\mathrm{bc}}$ \\
\hline & 60 day & $38.95 \pm 1.53^{\mathrm{bc}}$ & $13.49 \pm 1.58^{\mathrm{a}}$ & $14.71 \pm 5.08^{\mathrm{ab}}$ & $3.58 \pm 0.24^{\mathrm{a}}$ \\
\hline
\end{tabular}

${ }^{1)} \mathrm{CG}$, Gouda cheese of ripening without coating; VG, Gouda cheese of ripening after vacuum packaged; LG, Gouda cheese of laterite coating ripening ; RG, Gouda cheese of red loess coating ripening; YG, Gouda cheese of yellow ocher coating ripening; WG, Gouda cheese of white clay coating ripening; BG, Gouda cheese of black soil coating ripening.

${ }^{2)}$ All values are mean $\pm \mathrm{SD}$.

${ }^{3)}$ Means in the same column followed by different uppercase letters are significantly different $(p<0.05, a>b>c>d)$. 
Table 3. The $\mathrm{pH}$ and titratable acidity of Gouda cheese coated with loess during ripening period

\begin{tabular}{|c|c|c|c|}
\hline \multicolumn{2}{|c|}{ Samples } & \multirow{2}{*}{$\frac{\mathrm{pH}}{5.49 \pm 0.06^{923)}}$} & \multirow{2}{*}{$\begin{array}{c}\text { Titratable acidity }(\%) \\
0.115 \pm 0.005^{\text {efg }}\end{array}$} \\
\hline Before ripening & 0 day & & \\
\hline \multirow{2}{*}{$\mathrm{CG}^{1)}$} & 30 day & $6.47 \pm 0.01^{\mathrm{b}}$ & $0.096 \pm 0.005^{g}$ \\
\hline & 60 day & $7.01 \pm 0.01^{\mathrm{a}}$ & $0.156 \pm 0.011^{\mathrm{cd}}$ \\
\hline \multirow{2}{*}{ VG } & 30 day & $5.87 \pm 0.03^{\mathrm{c}}$ & $0.119 \pm 0.008^{\mathrm{efg}}$ \\
\hline & 60 day & $5.84 \pm 0.01^{\mathrm{cd}}$ & $0.214 \pm 0.004^{\mathrm{ab}}$ \\
\hline \multirow{2}{*}{$\mathrm{LG}$} & 30 day & $5.83 \pm 0.02^{\mathrm{cd}}$ & $0.107 \pm 0.008^{\mathrm{fg}}$ \\
\hline & 60 day & $5.75 \pm 0.01^{\mathrm{e}}$ & $0.184 \pm 0.022^{\mathrm{bc}}$ \\
\hline \multirow{2}{*}{ RG } & 30 day & $5.84 \pm 0.02^{\mathrm{cd}}$ & $0.148 \pm 0.007^{\mathrm{de}}$ \\
\hline & 60 day & $5.74 \pm 0.01^{\mathrm{ef}}$ & $0.126 \pm 0.015^{\mathrm{defg}}$ \\
\hline \multirow{2}{*}{ YG } & 30 day & $5.81 \pm 0.01^{\mathrm{d}}$ & $0.159 \pm 0.004^{\mathrm{cd}}$ \\
\hline & 60 day & $5.76 \pm 0.01^{\mathrm{e}}$ & $0.218 \pm 0.047^{7 \mathrm{~b}}$ \\
\hline \multirow{2}{*}{ WG } & 30 day & $5.85 \pm 0.03^{c}$ & $0.147 \pm 0.002^{\mathrm{de}}$ \\
\hline & 60 day & $5.71 \pm 0.01^{\mathrm{f}}$ & $0.191 \pm 0.055^{b c}$ \\
\hline \multirow{2}{*}{ BG } & 30 day & $5.83 \pm 0.01^{\mathrm{cd}}$ & $0.137 \pm 0.008^{\mathrm{def}}$ \\
\hline & 60 day & $5.74 \pm 0.01^{\mathrm{ef}}$ & $0.232 \pm 0.019^{\mathrm{a}}$ \\
\hline
\end{tabular}

${ }^{11} \mathrm{CG}$, Gouda cheese of ripening without coating; VG, Gouda cheese of ripening after vacuum packaged; LG, Gouda cheese of laterite coating ripening ; RG, Gouda cheese of red loess coating ripening; YG, Gouda cheese of yellow ocher coating ripening; WG, Gouda cheese of white clay coating ripening; BG, Gouda cheese of black soil coating ripening.

${ }^{2)}$ All values are mean $\pm \mathrm{SD}$.

${ }^{3}$ Means in the same column followed by different uppercase letters are significantly different $(\mathrm{p}<0.05, a>b>c>d>e>f>g)$.

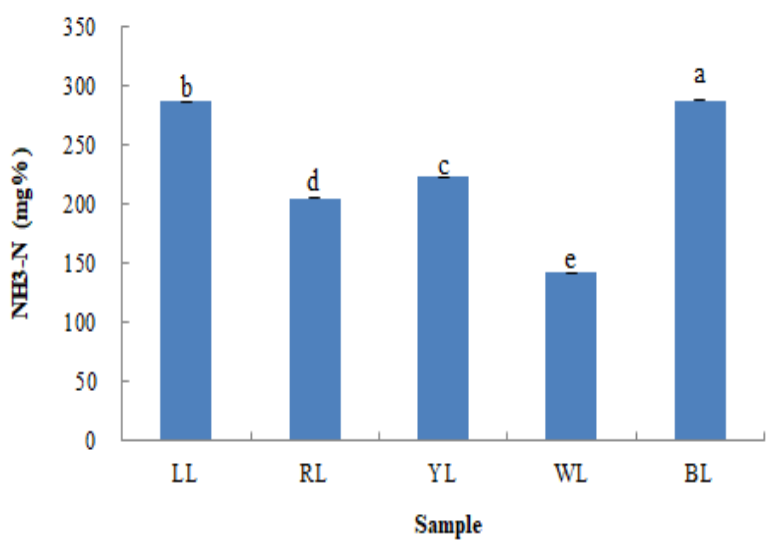

Fig. 3. $\mathrm{NH}_{3}-\mathrm{N}$ content in loess.

LL, Laterite; RL, Red loess; YL, Yellow ocher; WL, White clay; BL, Black soil. All values are mean $\pm \mathrm{SD}$. Means in the bar followed by different uppercase letters are significantly different $(\mathrm{p}<0.05, \mathrm{a}>\mathrm{b}>\mathrm{c}>\mathrm{d}>\mathrm{e})$.

\section{무기성분 함량}

가우다 치즈의 무기성분 측정 결과는 다음 Table 4와 같다. 제조 직후 가우다 치즈의 무기성분의 함량은 $\mathrm{Na}, \mathrm{Ca}$, $\mathrm{Mg}, \mathrm{K}$ 순으로 $\mathrm{Mg}$ 와 $\mathrm{K}$ 의 함량이 비슷하게 나타났으나, 이 후 30 일 및 60 일 숙성 가우다 치즈에서는 $\mathrm{Na}, \mathrm{Ca}, \mathrm{K}$, $\mathrm{Mg}$ 순으로 나타났다. 시료구별 무기성분에서 $\mathrm{Na}$ 함량은 제조 직후 $1,254 \mathrm{mg} \%$ 에서 진공 포장해 숙성 시킨 가우다 치즈를 제외한 그 외 시료구는 숙성 30 일과 60 일차에 모두 증가하는 경향을 보였다. 진공 포장해 숙성 시킨 가우다
치즈는 제조 직후 가우다 치즈의 $\mathrm{Na}$ 함량과 비슷한 함량을 보였으며, 이러한 결과는 앞서 수분 함량을 측정한 결과에 서 제조 직후 가우다 치즈의 수분 함량과 진공 포장해 30 일 과 60 일 숙성 시킨 가우다 치즈의 수분 함량이 유의적 차이 가 없었던 결과에서 수분 함량과 연관 지어 $\mathrm{Na}$ 함량이 비슷 한 함량을 나타낸 결과로 판단된다. 또한 시료구별 $\mathrm{Na}, \mathrm{K}$, $\mathrm{Ca}, \mathrm{Mg}$ 의 함량 차이를 보면 시료구별로 유의적 차이가 크 게 나타나 이는 사용된 황토의 종류에 따른 무기성분의 조성이 숙성 중의 치즈에 영향을 미쳤을 것으로 판단된다. 본 연구에서의 숙성 60 일째 모든 시료구의 무기성분 조성 은 농촌진흥청 국립농업과학원(27)에서 고시한 가우다 치 즈의 무기성분 조성과 비슷한 함량을 보여 품질의 차이는 크지 않은 것으로 확인 되었다.

\section{$\mathrm{NH}_{3}-\mathrm{N}$ 함량}

가우다 치즈의 NH3-N 측정 결과는 다음 Fig. 4 와 같다. 숙성 전 가우다 치즈의 NH3-N 함량은 $1,425 \mathrm{mg} \%$ 였으나, 숙성 30 일 차에 모든 시료구가 약 $2,100 \mathrm{mg} \%$ 대로 증가 하였고, 이후 60 일 숙성 가우다 치즈에서는 모든 시료구에 서 감소하는 것을 확인 할 수 있었으며, 이중 홍토로 코팅해 숙성한 가우다 치즈의 $\mathrm{NH}_{3}-\mathrm{N}$ 함량이 숙성 60 일째 가장 낮은 함량을 나타냈다. 시료구별 숙성 기간에 따른 $\mathrm{NH}_{3}-\mathrm{N}$ 함량 변화를 보면 코팅 없이 숙성시킨 가우다 치즈는 30 일 숙성 완료 후 약 $2,500 \mathrm{mg} \%$ 의 함량을 보였고 이후 60 일 
Table 4. The contents of minerals in Gouda cheese coated with loess during ripening period

$(\mathrm{mg} \%)$

\begin{tabular}{|c|c|c|c|c|c|}
\hline \multicolumn{2}{|c|}{ Samples } & \multirow{2}{*}{$\frac{\mathrm{Na}}{1,254.53 \pm 20.84^{\text {gh2/3) }}}$} & \multirow{2}{*}{$\begin{array}{c}\mathrm{K} \\
310.08 \pm 3.88^{\mathrm{i}}\end{array}$} & \multirow{2}{*}{$\frac{\mathrm{Ca}}{832.80 \pm 2.10^{\mathrm{d}}}$} & \multirow{2}{*}{$\frac{\mathrm{Mg}}{342.29 \pm 13.64^{\mathrm{abc}}}$} \\
\hline Before ripening & 0 day & & & & \\
\hline \multirow{2}{*}{$\mathrm{CG}^{1)}$} & 30 day & $1,335.29 \pm 17.32^{\mathrm{f}}$ & $342.04 \pm 8.32^{\mathrm{h}}$ & $954.69 \pm 10.98^{b}$ & $325.18 \pm 8.06^{\mathrm{bc}}$ \\
\hline & 60 day & $1,327.37 \pm 8.89^{f}$ & $542.64 \pm 22.99^{\mathrm{cd}}$ & $1,018.24 \pm 1.99^{\mathrm{a}}$ & $339.39 \pm 8.08^{\mathrm{abc}}$ \\
\hline \multirow{2}{*}{ VG } & 30 day & $1,186.41 \pm 7.80^{j}$ & $580.54 \pm 7.27^{\mathrm{b}}$ & $664.09 \pm 5.77^{\mathrm{h}}$ & $329.14 \pm 41.20^{\mathrm{bc}}$ \\
\hline & 60 day & $1,231.33 \pm 11.22^{\mathrm{hi}}$ & $571.09 \pm 2.67^{\mathrm{bc}}$ & $771.98 \pm 6.49^{f}$ & $328.84 \pm 17.27^{\mathrm{bc}}$ \\
\hline \multirow{2}{*}{ LG } & 30 day & $1,341.30 \pm 5.79^{\mathrm{f}}$ & $593.92 \pm 46.88^{\mathrm{ab}}$ & $830.91 \pm 3.59^{\mathrm{de}}$ & $278.65 \pm 74.27^{\mathrm{de}}$ \\
\hline & 60 day & $1,314.08 \pm 11.18^{\mathrm{f}}$ & $500.27 \pm 4.66^{\mathrm{ef}}$ & $697.24 \pm 10.57^{g}$ & $308.83 \pm 2.48^{\text {cd }}$ \\
\hline \multirow{2}{*}{ RG } & 30 day & $1,208.97 \pm 11.28^{\mathrm{ij}}$ & $491.24 \pm 2.96^{\mathrm{f}}$ & $555.43 \pm 4.44^{j}$ & $372.74 \pm 4.44^{\mathrm{ab}}$ \\
\hline & 60 day & $1,685.83 \pm 28.65^{\mathrm{c}}$ & $615.77 \pm 35.60^{\mathrm{a}}$ & $580.47 \pm 17.60^{\mathrm{i}}$ & $317.32 \pm 22.90^{\text {cd }}$ \\
\hline \multirow{2}{*}{ YG } & 30 day & $1,508.90 \pm 19.16^{\mathrm{e}}$ & $493.38 \pm 18.33^{\mathrm{f}}$ & $550.94 \pm 10.56^{j}$ & $338.70 \pm 5.64^{\mathrm{abc}}$ \\
\hline & 60 day & $1,761.12 \pm 16.39^{\mathrm{a}}$ & $544.17 \pm 5.68^{\text {cd }}$ & $957.49 \pm 10.96^{b}$ & $262.43 \pm 9.10^{\mathrm{e}}$ \\
\hline \multirow{2}{*}{ WG } & 30 day & $1,271.32 \pm 1.46^{g}$ & $528.88 \pm 19.09^{\mathrm{de}}$ & $505.71 \pm 6.12^{\mathrm{k}}$ & $350.91 \pm 11.65^{\mathrm{abc}}$ \\
\hline & 60 day & $1,731.55 \pm 17.97^{\mathrm{b}}$ & $538.97 \pm 1.03^{\text {cd }}$ & $815.58 \pm 8.88^{\mathrm{e}}$ & $313.82 \pm 6.68^{\text {cd }}$ \\
\hline \multirow{2}{*}{ BG } & 30 day & $1,549.76 \pm 14.71^{\mathrm{d}}$ & $407.03 \pm 2.27^{\circ}$ & $897.88 \pm 8.91^{\mathrm{c}}$ & $377.16 \pm 1.70^{\mathrm{a}}$ \\
\hline & 60 day & $1,682.08 \pm 27.12^{\mathrm{c}}$ & $511.56 \pm 5.56^{\text {def }}$ & $674.24 \pm 17.67^{\mathrm{h}}$ & $338.29 \pm 20.04^{\mathrm{abc}}$ \\
\hline
\end{tabular}

${ }^{1} \mathrm{CG}$, Gouda cheese of ripening without coating; VG, Gouda cheese of ripening after vacuum packaged; LG, Gouda cheese of laterite coating ripening ; RG, Gouda cheese of red loess coating ripening; YG, Gouda cheese of yellow ocher coating ripening; WG, Gouda cheese of white clay coating ripening; BG, Gouda cheese of black soil coating ripening.

${ }^{2)}$ All values are mean $\pm \mathrm{SD}$

${ }^{3)}$ Means in the same column followed by different uppercase letters are significantly different $(p<0.05, a>b>c>d>e>f>g>h>i>j>k)$.

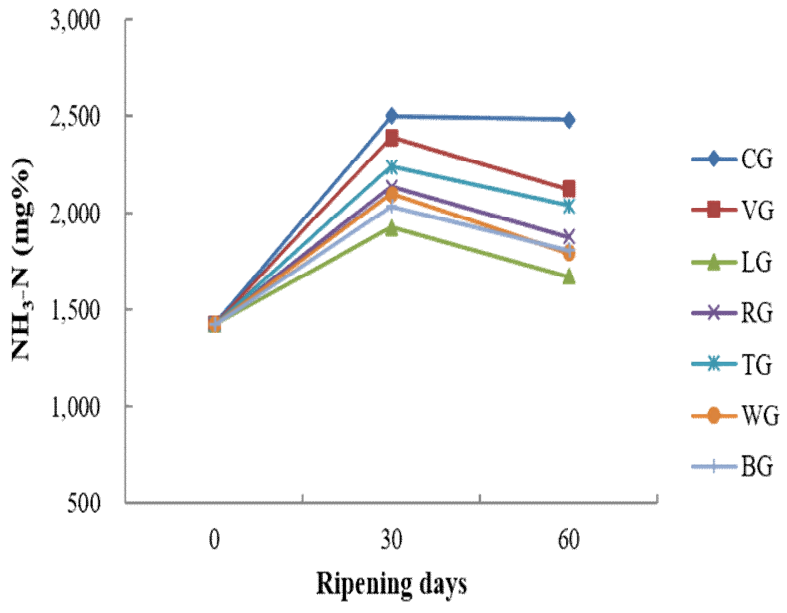

Fig. 4. The contents of $\mathrm{NH}_{3}-\mathrm{N}$ in Gouda cheese coated with loess during ripening period.

CG, Gouda cheese of ripening without coating; VG, Gouda cheese of ripening after vacuum packaged; LG, Gouda cheese of laterite coating ripening ; RG, Gouda chese of red loess coating ripening; YG, Gouda cheese of yellow ocher coating ripening; WG, Gouda cheese of white clay coating ripening; BG, Gouda cheese of black soil coating ripening. All values are mean $\pm \mathrm{SD}$.

숙성에서도 약 $2,480 \mathrm{mg} \%$ 로 약 $20 \mathrm{mg} \%$ 의 적은 량의 $\mathrm{NH}_{3}-\mathrm{N}$ 가 제거 된 것을 확인 할 수 있었다. 또 진공 포장 숙성 가우다 치즈의 경우 30 일 차에서 약 $2,390 \mathrm{mg} \%$ 에서 60 일 차에 $2,120 \mathrm{mg} \%$ 로 약 $270 \mathrm{mg} \%$ 의 $\mathrm{NH}_{3} \mathrm{~N}$ 가 제거 되었으며, 황토 시료구에서 숙성 30 일 차와 숙성 60 일 차를 비교하였
을 때 백토로 코팅해서 숙성한 가우다 치즈가 약 $300 \mathrm{mg} \%$ 로 가장 많은 감소폭을 보였고, 그 다음으로 적황토로 코팅 해 숙성한 가우다 치즈가 $258 \mathrm{mg} \%$ 의 감소폭을 보였다. 숙성기간 중 30 일 차에서 $\mathrm{NH}_{3}-\mathrm{N}$ 의 함량이 증가하는 것은 황토 자체가 보유한 $\mathrm{NH}_{3}-\mathrm{N}$ 성분과 치즈가 숙성 되면서 생성된 $\mathrm{NH}_{3}-\mathrm{N}$ 성분으로 인하여 함량이 증가한 것으로 생각 되어 지며, 이후 60 일 차에서는 $\operatorname{Lee(30)ㅇㅢ~ㅂㅗㄱㅗㅇㅔㅅㅓㅇㅘ~ㄱㅏㅌㅇㅣ~}$ 황토의 비표면적과 세공분포 및 황토 표면의 음전하에 의해 황토가 암모니아가스를 흡착함으로 인하여 $\mathrm{NH}_{3}-\mathrm{N}$ 함량이 감소한 것으로 생각되어 진다.

\section{중금속 함량}

가우다 치즈의 숙성에 활용된 황토의 경우 토양 성분으 로써 속에 존재하는 다양한 중금속에 대한 문제점을 제기할 수 있다. 따라서 본 연구에서는 황토를 코팅해 숙성시키는 시스템을 개발하는 과정에서 치즈의 안전성을 확보하고자 숙성 60 일째의 치즈들에 대한 중금속 함량을 측정하였으며 그 결과는 Table 5와 같다. 모든 시료구에서 $\mathrm{Cu}$ 가 검출되었 으며, 홍토로 코팅하여 숙성시킨 가우다 치즈에서만 $\mathrm{Pb}$ 가 검출되었다. 식품의약품안전처(31)에 고시된 바에 의하면 $\mathrm{Pb}$ 의 경우 우리나라에서는 $0.02 \mathrm{mg} / \mathrm{kg}$ 으로 제한하고 있고, $\mathrm{Cu}$ 의 경우 허용섭취량이 $0.05-0.5 \mathrm{mg} / \mathrm{kg}$ 사이로 모든 중금 속 성분에 대해 적합한 것을 확인 할 수 있었다. 
Table 5. The content of heavy metals after ripening of Gouda cheese coated with loess

$(\mathrm{mg} / \mathrm{L})$

\begin{tabular}{cccccccc}
\hline Sample & $\mathrm{Pb}$ & $\mathrm{Cd}$ & $\mathrm{As}$ & $\mathrm{Hg}$ & $\mathrm{Sn}$ & $\mathrm{Cr}$ & $\mathrm{Cu}$ \\
\hline $\mathrm{CG}^{\mathrm{l}}$ & -2 & - & - & - & - & - & $0.142 \pm 0.001^{\mathrm{c}}$ \\
VG & - & - & - & - & - & - & $0.079 \pm 0.001^{\mathrm{g}}$ \\
LG & $0.005 \pm 0.006^{334)}$ & - & - & - & - & - & $0.152 \pm 0.000^{\mathrm{b}}$ \\
RG & - & - & - & - & - & - & $0.134 \pm 0.001^{\mathrm{d}}$ \\
YG & - & - & - & - & - & - & $0.116 \pm 0.000^{\mathrm{e}}$ \\
WG & - & - & - & - & - & $0.183 \pm 0.001^{\mathrm{a}}$ \\
BG & - & - & - & - & - & - & $0.089 \pm 0.001^{\mathrm{f}}$ \\
\hline
\end{tabular}

${ }^{1)} \mathrm{CG}$, Gouda cheese of ripening without coating; VG, Gouda cheese of ripening after vacuum packaged; LG, Gouda cheese of laterite coating ripening ; RG, Gouda cheese of red loess coating ripening; YG, Gouda cheese of yellow ocher coating ripening; WG, Gouda cheese of white clay coating ripening; BG, Gouda cheese of black soil coating ripening.

${ }^{2}$ Not detected.

${ }^{3)}$ Means in the same column followed by different uppercase letters are significantly different $(\mathrm{p}<0.05, \mathrm{a}>\mathrm{b}>\mathrm{c}>\mathrm{d}>\mathrm{e}>\mathrm{f}>\mathrm{g})$.

${ }^{4)}$ All values are mean $\pm \mathrm{SD}$.

\section{요 약}

본 연구는 천연 소재인 황토를 이용하여 치즈 숙성 중 오염원인 곰팡이균 제거 기술을 개발하고자 이 연구를 수행 하였다. 황토의 품질을 측정한 결과 수분함량은 홍토 $3.48 \%$, 흑토 $3.31 \%$, 적황토 $1.56 \%$, 호황토 $0.95 \%$, 백토 $0.22 \%$ 로 홍토의 수분 함량이 가장 높게 나타났으며 백토가 가장 낮은 수분함량으로 나타났고, 항곰팡이 효과를 측정 한 결과는 백토의 항곰팡이 효과가 약간 높게 나타났다. 황토의 중금속 측정결과 토양 오염 우려기준 및 대책 기준 에 적합한 것을 확인 할 수 있었다. 황토의 $\mathrm{NH}_{3} \mathrm{~N}$ 함량은 백토의 $\mathrm{NH}_{3}-\mathrm{N}$ 함량이 $143.51 \mathrm{mg} \%$ 로 가장 낮은 함량을 보였으며, 그 다음으로 적황토가 $204.88 \mathrm{mg} \%$ 로 낮은 함량 을 보였다. 숙성 기간에 따른 가우다 치즈의 일반성분 측정 결과 수분, 조지방, 조단백, 조회분 순으로 나타났다. 가우 다 치즈는 수분 함량이 25-36\% 내외로 고시된 경질 치즈에 해당 되는 치즈로써 본 연구에서의 60 일 숙성 후 수분 함량 측정 결과 백토로 코팅해 숙성한 가우다 치즈만 범위 내에 있었다. 숙성중 치즈의 $\mathrm{pH}$ 와 적정산도는 전체적으로 모든 시료구에서 증가하는 경향을 보였다. 무기성분 조성은 $\mathrm{Na}$, $\mathrm{Ca}, \mathrm{Mg}, \mathrm{K}$ 순으로 나타났다. $\mathrm{NH}_{3}-\mathrm{N}$ 함량은 홍토로 코팅해 숙성한 가우다 치즈의 $\mathrm{NH}_{3}-\mathrm{N}$ 함량이 숙성 60 일째 가장 낮은 함량을 나타냈고, 백토로 코팅해서 숙성한 가우다 치 즈는 숙성 30 일째에서 60 일째 $\mathrm{NH}_{3}-\mathrm{N}$ 함량 변화에서 300 $\mathrm{mg} \%$ 로 가장 많은 감소폭을 보였다. 황토를 코팅해 숙성시 키는 시스템을 개발하는 과정에서 치즈의 안전성을 확보하 고자 숙성 60 일째의 치즈들에 대한 중금속 함량을 측정한 결과 식품의약품안전처에 고시된 내용에 적합한 것을 확인 할 수 있었다. 이를 통해 기존 가우다 치즈를 왁스 코팅하여 숙성할 시 자주 뒤집어 주어야 하는 숙성 과정의 번거로움
을 해소시키고 숙성 과정에서 발생하는 곰팡이 균 생성을 최소화함으로써 숙성 치즈 생산 효율을 높일 수 있을 것으 로 생각되어 지며, 더 나아가서는 이와 같은 방법을 다른 숙성 치즈의 숙성 방법에 응용함으로써 국내 숙성 치즈 제조 기술 발전에 기여할 수 있을 것으로 생각되어 진다.

\section{감사의 글}

본 연구는 한국연구재단(과제번호 : 2017R1C1B5074216) 의 연구비 지원을 받아 실행한 결과의 일부로 이에 감사드 립니다.

\section{References}

1. Lee SW, Nam MS (1996) Change in the casein, free amino acid and textures during ripening of gouda cheese. Food Sci Anim Resour, 16, 35-40

2. Lee SW, Nam MS (1996) Change in chemical composition and nitrogenous compounds during ripening of gouda cheese. Food Sci Anim Resour, 16, 41-46

3. Alewijn M, Sliwinski EL, Wouters JTM (2005) Production of fat-derived (flavour) compounds during the ripening of gouda cheese. Int Daily J, 15, 733-740

4. Choi HY, Yang CJ, Choi KS, Bae I (2015) Characteristics of gouda cheese supplemented with fruit liquors. J Anim Sci Technol, 57, 1-13

5. Choi HY (2011) Application in gouda-type cheese manufacture added with korea traditional wines. MS 
Thesis, Sunchon National University, Korea, p 1-113

6. Honish L, Predy G, Hislop N, Chui L, KowalewskaGrochowska K, Trottier L, Kreplin C, Zazulak I (2005) An outbreak of $E$. coli $\mathrm{O} 157: \mathrm{H} 7$ hemorrhagic colitis associated with unpasteurized gouda cheese. Can J Public Health, 96, 182-184

7. Van Hoorde K, Verstraete T, Vandamme P, Huys G (2008) Diversity of lactic acid bacteria in two flemish artisan raw milk gouda-type cheeses. Food Microbiol, 25, 929-935

8. Korea Agro-Fisheries \& Food Trade Coporation (2015) 2015 Segment Market Report-Butter and Cheese Market, Food Information Statistics System 11-1543000-001037-01, NaJu, Korea, p 66

9. Kim NO (1992) Studies on the gouda cheese qualities depending on the ripening periods. MS thesis, Konkuk University, Korea, p 1-30

10. Kim JH, Kim BM, Jeong SG, Oh MH (2017) The Prevalence and Control of Spoilage Mold and Yeast in Cheese. J Milk Sci Biotechnol, 35, 152-161

11. Grappin R, Rank TC, Olson NF (1985) Primary proteolysis of cheese proteins during ripening. A Review. J Dairy Sci, 68, 531-540

12. Yamauchi K, Igoshi K, Kaminogawa S (1986) Purification and property of proteinases with an ouptimum $\mathrm{pH}$ at 8.0 from gouda type cheese and its comparition with milk proteinases. Anim Sci J, 58, 516-527

13. Pena Leon Pieleu-ibeu (2014) Method for coating cheese products. Korea Patent No. KR20150139577A

14. Hwang JY (1997) Characteristics and utilization of loess and barley stone. J Miner Soc Korea Symposium Resource Book. 89-99

15. Seo Y, Yoon S, Kim S, Cho W, Lee S, Kang H, Yoon M, Park J, Yoo B, Chang Y, Lee Y (2014) Quality characteristics of radish treated with environmentally-friendly red clay-processed materials. J Korean Soc Food Sci Nutr, 43, 1394-1399

16. Seo Y, Gil B, Kyoung J, Yoo B, Chang Y, Yu S, Lee $Y$ (2014) Effect of environmetally-friendly red clay-processed materials on quality characteristics of eel. J Korean Soc Food Sci Nutr, 43, 287-292

17. Park JG, Yoon MY (2014) Methods of preparing red clay processed material and alkali ionized water. Korea Patent No. KR101395812B1

18. Kang HS (2012) Humidity control and deodorization effect of hwangto plastering according to the finishing material. MS thesis, Chonbuk National University, Korea, p 1-74

19. AOAC (1990) Official methods of analysis. 15th ed, Association of official analytical chemists, Washington DC, USA, p 5

20. Kang SC, Koo BS, Tae UH (2002) Effects of Loess on the mycellial pellet formation of phosphate-solubilizing fungus, Aspergillus sp. PS-104 in the submerged culture. Korean J Environ Agric, 21, 17-23

21. KFDA (2007) Test method in general. Int'1 Food code(separate volume), Korea food and drug administration, Cheongju, Korea, p 1267

22. Hwang JH (2010) The fermentative characteristics of cheonggukjang prepared by starter culture of Bacillus spp. with fibrinolytic activi. Prev Nutr Food Sci, 39, 1832-1838

23. Park IH (2014) The study on recent distribution and change of specific and relative humidity over the republic of korea, MS Thesis, Konkuk University, Korea, p 1-53

24. Byrne GS, Ward OP (1989) Effect of nutrition on pellet formation by Rhizopus arrhizus. Biotechnol Bioeng. 33, 912-914

25. Lee EM (2008) Anti-microbial activities of white clay. MS Thesis, Chung-ang University, Korea, p 1-48

26. Soil Environment Center, http://www.sec.re.kr/info/ policy_02/board/list.do?searchCate1 =PC020101, (accessed April 2019)

27. Rural development administration, National institute of agricultural sciences, (2016), $9^{\text {th }}$ revision Korea Food Composition Table, Wanju, Korea, p 382

28. Ham JS, Jeong SG, Kim HS, Hong KH, Cho EJ, Ahn JN, Lee JM (2003) Studies on the textural characteristics and the standard for cheese products. Korean J Food Sci Ani Resour, 23, 70-74

29. Choi H, Kim G, Chun S, Bae I (2011) Quality properties of appenzeller cheese added with fish surimi, Food Sci Anim Resour. 31, 232-240

30. Lee BL (2016) An assessment on environmental performance of hwangtoh through penicillium and water flea exposure experiment. MS Thesis, Chonbuk National University, Korea, p 1-60

31. Korea Food \& Drug Administration (2012) Study of heavy metals in food safety control, Final Report of KIST, KIST 1475009081 